October 2017

\title{
Presumed Consent for Organ Donation: Principlism Opts Out
}

Ryan M. Marquardt

Cedarville University

Follow this and additional works at: http://digitalcommons.cedarville.edu/

bioethics_in_faith_and_practice

Part of the Bioethics and Medical Ethics Commons, and the Health Services Administration Commons

DigitalCommons@Cedarville provides a publication platform for fully open access journals, which means that all articles are available on the Internet to all users immediately upon publication. However, the opinions and sentiments expressed by the authors of articles published in our journals do not necessarily indicate the endorsement or reflect the views of DigitalCommons@Cedarville, the Centennial Library, or Cedarville University and its employees. The authors are solely responsible for the content of their work. Please address questions to dc@cedarville.edu.

\section{Recommended Citation}

Marquardt, Ryan M. (2017) "Presumed Consent for Organ Donation: Principlism Opts Out," Bioethics in Faith and Practice: Vol. 3 : No. 1 , Article 5. 


\title{
Presumed Consent for Organ Donation: Principlism Opts Out
}

Browse the contents of this issue of Bioethics in Faith and Practice.

Please read the Senior Editor's Preview for his insight about this article.

\author{
About the Author(s) \\ Ryan Marquardt graduated from Cedarville University in 2017 with a B.S. in Molecular and Cellular Biology \\ and minors in Bioethics and Bible. He plans to continue his education, seeking a Ph.D. in the biomedical \\ sciences with the intention of entering the research field.
}

\section{Institution/Affiliation}

Cedarville University

\begin{abstract}
The number of available organs for transplant each year falls woefully short of the number of patients in need of donated organs in the United States. While approval numbers are very high for organ donation, the number of registered donors is much smaller. A commonly proposed solution to increase the pool of organ donors is to replace the current explicit consent policy with a presumed consent system, where everyone is considered to have consented as a donor unless they have opted out by joining a non-donor registry or by some other method. This proposal raises many ethical questions that must be examined in light of standard medical ethics principles before implementation of such a policy should be supported. On a practical level, the evidence for the results of putting presumed consent policy in place should first be analyzed. Careful consideration of such evidence reveals that implementation of presumed consent in the United States may raise donor rates, but this result is not at all as guaranteed as many proponents claim. Under principlism, a common ground bioethics approach, presumed consent is morally questionable at best. Examination with regards to the four pillars of principlism, beneficence, non-maleficence, justice, and autonomy, reveals considerable ethical difficulties that all but disqualify presumed consent from consideration. While it is possible that such a system would increase organ donation rates, it increases the potential for discrimination in the donation process, is likely to subvert doctor-patient trust in some cases, and undermines the concept of true informed consent in medicine.
\end{abstract}

\section{Keywords}

Organ donation, organ transplantation, presumed consent, opt out policy, principlism, informed consent, patient autonomy, health care policy

\section{Creative Commons License}

(c) (1) ()

This work is licensed under a Creative Commons Attribution-Noncommercial-No Derivative Works 4.0 License. 


\title{
Presumed Consent for Organ Donation: Principlism Opts Out
}

\author{
Ryan Marquardt \\ Cedarville University
}

\section{Introduction}

The State of the Organ Shortage

Most people know transplantable organ shortage is a monumental problem in the United States and around the world. Ever since the first successful kidney transplant at Boston's Brigham \& Women's Hospital in 1954, the need for donors has been apparent. ${ }^{1}$ Once effective anti-rejection drugs became readily available in the late 1970s and transplants became routine, the organ shortage became as much a social issue as a medical issue. ${ }^{2}$ Even though new research and technology has only made transplants safer and more successful, a transplant's chances of success are irrelevant without an available donor. According to Organ Procurement and Transplantation Network data as of March 23, 2017, 118,049 candidates are waiting for a transplant in the United States. From 2012-2016, 267,177 new candidates were added to waiting lists, but only 151,132 transplants from 73,702 donors took place, which is possible because a single deceased donor can supply several organs for transplant. That means that each year, the theoretical gap between those in need of organs and organs available increased by over 20,000 on average. ${ }^{3}$ Now, we do not actually see this kind of an expanding shortage over time in reality because many candidates $(21,237$ in 2016) are removed from waiting lists for reasons other than the receipt of a transplant, such as death or improved condition, but that fact is hardly any comfort. More than any other statistic, the fact that in those five years 31, 853 Americans died waiting for a transplant speaks to the tragedy of the current situation. ${ }^{4}$

Understanding the need for more organs is only the first step to remedying the problem, and it is a small one. While the possibility remains that science could provide the solution in the form of so-called 'organs in a dish' or mechanical substitutes, thousands die waiting for science to fix a problem that need not exist. While it is difficult to fault healthy people for not becoming living donors, these only account for about $37 \%$ of total donors and $18 \%$ of transplants, due to the fact that a deceased donor can provide up to eight vital organs. ${ }^{5}$ Far more organs are lost due to a lack of willingness to donate after death. A 2003 study estimated that in the U.S. from 1997-1999, potentially life-saving organs from 58\% of possible donors were buried. ${ }^{6}$ There is little reason to believe the situation has changed, as 95\% of American adults support organ donation, but only $51 \%$ were registered donors in $2016 .{ }^{7}$ Even with all this data, the overall shortage can only be estimated and is difficult to quantify, but the problem is obvious nonetheless. The argument can be made that the supply will never meet the demand due to the rapidly rising need for organs, but that in no way reduces the value of endeavoring to close the gap. ${ }^{8}$ A life saved is a life saved.

\section{The Proposal of Presumed Consent}

With the state of the organ donor shortage clearly laid out, we can begin to consider the effectiveness and ethicality of possible solutions. A common proposal to close the gap between organ donation approval and registration that has been implemented in several European countries and heavily discussed in the United States and the UK is an 'opt out' or presumed consent system. This type of arrangement would provide all adults with a mechanism to join a non-donor registry and take failure to join as consent to donate. ${ }^{9}$

While some believe that changing from explicit consent to presumed consent would not significantly increase the donor rate, most objections to presumed consent are made on ethical grounds.

Bioethics in Faith and Practice vol. 3, no. 1, pp. 11-22. ISSN 2374-1597

(C) 2017, Ryan Marquardt, licensed under CC BY-NC-ND

(http://creativecommons.org/licenses/by-nc-nd/4.0/) 
While several distinct, insightful moral frameworks could reasonably be chosen to analyze the ethics of presumed consent, for the sake of coherence and brevity, this paper will evaluate the policy only from the ethical framework termed 'principlism.' In the author's opinion, this system is the best choice because it is tailored to bioethics discussions, is practical and easy to apply to specific scenarios, and is a commonground approach that attempts to use principles that are largely agreed upon by major ethical systems such as utilitarianism, Kantian deontology, natural law theory, Divine Command Theory, and virtue ethics. This system also garners much support in the medical community, being rooted in tradition that reaches all the way back to Hippocrates and codified in international law. ${ }^{10}$ Principlism bases ethical determinations on the four principles of autonomy, beneficence, non-maleficence, and justice, which this paper will explore individually later on in the context of presumed consent. Before getting into a discussion of ethics, we will review current organ donation policy in the U.S. and touch on the likely impact implementation of a presumed consent system would have. At that point, this paper will examine presumed consent in light of each of the four pillars of principlism and will conclude that while commitment to a presumed consent organ donor list is tempting due to its potential to save lives, it fails to be ethically justifiable under principlism.

\section{Would Presumed Consent Work in the United States? Current United States Policy}

Currently the U.S. operates on an explicit consent system, which means either an individual must consent to organ donation before death, or the individual's family must give permission if no prior decision is documented. Since 1987, 'required request' policy has mandated that whenever a deceased potential donor has not made an explicit decision one way or the other, medical personnel are required to discuss donation as a possibility with a family member or legal representative. ${ }^{11}$ In 2006, the Revised Uniform Anatomical Gift Act (UAGA) was issued by the National Conference of Commissioners on Uniform State Laws, which recommends nonpartisan procedural legislation to states. The UAGA enacts the first person authorization (FPA) rule, which means a person's wishes expressed by signing a donor card or other official document, like a driver's license, or by joining a donor registry may not be revoked by the family. ${ }^{12}{ }^{13}$ All but four states have adopted the UAGA, and the remaining four have enacted FPA individually. ${ }^{14} 15$

Though the policy seems clear on paper, some evidence indicates that FPA is not always enforced. The team that actually removes organs from a deceased individual is part of an Organ Procurement Organization (OPO) and is intentionally separate from the medical team responsible for the patient's care and declaration of death by neurological or cardiac criteria. A 2014 blinded survey of the 58 OPOs nationwide revealed that only about $80 \%$ claim to conform to FPA, $49 \%$ assert that impact on family is either somewhat likely or very likely to impact organ procurement, and $9 \%$ overtly report that they are not likely to procure organs in the case that the potential donor is registered but the family objects. ${ }^{16}$ Other factors that influenced $29 \%$ or more of OPOs practice were effect on donor rates, potential legal liability, and adverse publicity. ${ }^{17}$ Fortunately, most OPOs estimated that a conflict between the wishes of the donor and the family occurred in less than $10 \%$ of cases. ${ }^{18}$ In short, although a person's wish to donate is now legally guaranteed even if the family objects, it is not always carried out in practice.

The change from explicit consent to a presumed consent system would significantly alter the current procedure. While presumed consent could play out several different ways when it comes to procedural details, it would at a minimum change the way the family is approached. They may simply be informed rather than asked if organs may be taken from their loved one, or the topic may be ignored altogether. A soft presumed consent law would allow the family to object to organ removal, while hard presumed consent would allow only the donor candidate to opt out before death. 
One important note at this point is that some object to the interchangeable use of the terms 'presumed consent' and 'opt out.' For example, T.M. Wilkinson, a political philosopher from the University of Auckland, argues that presumed consent implies the justification of non-explicit consent, while failure to opt out could instead be due to indecision or apathy. ${ }^{19}$ This paper will use the terms interchangeably, although the ethical implications of the difference will be discussed later on.

\section{Impact of Presumed Consent}

Before diving into the analysis of an opt out system for organ donation based on principlist medical ethics, it is worth considering an appeal to an ethic of pragmatism. In other words, it is important to know whether or not changing to this policy would actually increase the number of organ donors in the United States. If not, maybe the ethical debate is a waste of time. Common sense would argue that since $95 \%$ support organ donation, apathy is the most obvious reason only $51 \%$ are registered. If that is the case, requiring that action be taken to be a non-donor rather than requiring a positive step to become a donor would in theory push the donor rate up near $95 \%$. However, there could be other explanations for a lack of registration in those who support donation, such as support for the practice in general without personally being comfortable with having organs removed, fear of reduced effort on the part of medical personnel to save a donor, or the desire to default to what family members think is best. Public opinion of an opt out system would also likely impact its success, as very low approval could provoke backlash. In 2012, the US Department of Health and Human Services inquired about presumed consent in their national survey of organ donation attitudes and behaviors. They found that $51.1 \%$ either supported or strongly supported a change to presumed consent, which was up nearly $10 \%$ from their 2005 data. ${ }^{20}$ This number is unfortunately difficult to apply to an estimated effect of enacting presumed consent. If the majority of the $46.6 \%$ of people who opposed or strongly opposed presumed consent were already registered donors, changing the system could cause some of them to change their minds on principle, but if most of the people opposed were not already registered donors, changing the policy would probably have little effect. ${ }^{21}$ Either way, with public opinion near 50/50, it is difficult to use it as an evaluative tool.

The best way to predict the results of implementing presumed consent would seemingly be to look at countries that have implemented it, compare the number of donors in that country before and after the change, and compare the numbers in that country to other countries that use explicit consent. One such study utilizes a panel of 13 presumed consent and 9 explicit consent countries to make a comparison. ${ }^{22}$ While the straight comparison does not yield significant results, other factors must be noted. For example, commonly held religious beliefs in a certain region would likely impact donation rates, whether in a positive or negative way. Additionally, the rates of death by motor vehicle accident and cerebro-vascular diseases also vary by region and greatly impact the number of potential donors available. Controlling for these and other factors results in the statistically significant conclusion that cadaveric donation rates are $25-30 \%$ higher on average in presumed consent countries. ${ }^{23}$ A more recent meta-analysis focuses on five studies comparing donation rates before and after the introduction of presumed consent and four studies comparing donation rates in countries with presumed consent versus explicit consent. ${ }^{24}$ All of the before and after studies showed an increase in the number of donors; however, the authors note that these studies do not account well for other factors such as simultaneous infrastructure changes and increased publicity. Similarly, all of the comparison studies showed correlation between presumed consent and higher organ donation rates, three of which exhibited statistical significance. Again, the authors of the meta-analysis note that significant correlations also exist between higher donation rates and factors such as higher healthcare expenditure, high rates of Catholicism, and common law rather than civil law. The authors ultimately conclude that presumed consent is associated with higher donor rates, but it cannot be inferred that a change would lead to increased rates for every country. 
While the data indicate that implementing presumed consent may possibly increase donor rates, several mitigating factors not yet mentioned warrant consideration. First, one author argues that Spain, the country with the world's highest donor rates and counted as a presumed consent country in the studies above, does not truly operate on a presumed consent system. ${ }^{25}$ Further scrutiny shows that Spain's introduction of presumed consent legislation, approved by parliament in $1979^{26}$, did not produce a significant effect, so major organizational and infrastructure changes were made ten years later. At that point, Spain's donor rates began to increase to what they are today. In fact, the Director of the Spanish Organ Donation Organisation co-authored a paper in 2010 that asserts the presumed consent legislation in Spain is not enforced, and further investigation reveals that written consent of the family is actually required before organ removal can proceed. ${ }^{27}$ Since donor rates did not increase until organizational changes led to better awareness and societal acceptance of organ donation, the true explanation of Spain's high donor rates seems to be their cultural acceptance and $85 \%$ family acceptance rate. ${ }^{28}$ Another reason that data from other countries might not apply well to the U.S. is based on current policy and enforcement. Since first person authorization law technically overrides the desires of the family if a donor is registered, and it is still not evenly enforced by OPOs, switching to a soft presumed consent system where families always have the right to veto donation could end up resulting in the loss of the ability to overrule a family who disagrees with the donor's prior decision to donate. The solution to this could be to instead use a hard presumed consent rule where the family cannot opt a person out, but this seems likely to provoke public backlash. On the whole, data seems to show that implementing presumed consent may increase the number of organ donors; however, the numbers are far from conclusive due to the impossibility of controlling for all factors. Nonetheless, if increasing donor numbers were the only concern in crafting policy, presumed consent would probably be worth trying. That being the case, ethics are worth considering before coming to a final decision on presumed consent.

\section{Principlism and Presumed Consent Beneficence}

"I will use treatment to help the sick according to my ability and judgment," states the Hippocratic Oath. ${ }^{29}$ While this principle seems obvious as the basic premise of medicine, implementation can be complex in practice. Beneficence is a complicated topic when applied to organ donation because multiple parties have an interest to consider. The primary consideration is always the patient at hand; indeed the American Medical Association Principles of Medical Ethics states that "a physician shall, while caring for a patient, regard responsibility to the patient as paramount." ${ }^{30}$ Nevertheless, this principle does not apply to a donor candidate in the normal, straightforward way because the primary medical team has already declared the person dead. Nonetheless, respecting the desires of a patient could still arguably be required by beneficence. Where the situation becomes even more muddled is when the potential recipients are considered. It could be argued that when a patient dies and medical personnel can no longer help that person, their responsibility goes to helping another patient, namely one who could benefit from the organs of the decedent. Indeed, one formulation of beneficence states that "One has an obligation to prevent serious evil or harm when one can do so without seriously interfering with one's life plans or style and without doing any wrongs of commission." 31 One might argue from this that the organ procurement organization has the obligation to prevent harm to patients who need organs by giving them organs from the patient who has died and can no longer be physically harmed. On the other hand, others might argue that the possibility of transgressing the will of the deceased donor candidate is truly a "wrong of commission" which would then negate the obligation under beneficence. Indeed, though it is a reasonable expectation under beneficence that donor candidates have regard for the common good and the specific good of potential recipients, that type of beneficence is the prerogative of the donor and no one else. The idea of presuming consent adds another layer. Making an unfounded assumption about what a deceased patient would have desired is not supported by the obligation to respect living wishes. Nonetheless, the obligation to help patients languishing on the transplant list when the only possible harm could be to a deceased individual will be persuasive to some. If 
the potential donor is either opposed to donation or her desires are unknown, a conflict arises between beneficence to the donor and to the recipient, and no decision can be made based solely on beneficence. One other possible application of beneficence remains. In theory, if a presumed consent system were enacted, a subtle shift in the attitudes of medical personnel could take place. Since the working assumption would shift to the notion that every patient is a donor unless evidence says otherwise, doctors could be tempted more frequently to refrain from using every effort to save a patient who they do not expect to return to a high quality of life. Although the principle of 'decoupling' must be followed by hospital staff, meaning the decision to harvest organs must be separated from the determination of death, subtle shifts in thinking may still occur. ${ }^{32}$ When saving several lives is possible at the expense of one that could only maintain minimal quality of life, utilitarian calculations become enticing. Yet, beneficence requires doing everything in one's power to help the patient at hand, and a presumed consent system could subtly erode that way of thinking. All in all, there are too many unknowns and competing interests involving beneficence to use it alone for a judgment of presumed consent. Thus, one must default to the input of another moral principle.

\section{Non-maleficence}

Primum non nocere, or "first, do no harm," is perhaps the first principle most people would think of when broaching the topic of medical ethics. Though this exact phrase is not found in the Hippocratic Oath, the assumption is there, and common sense cements it as an important medical principle. Some of the same difficulties seen in applying beneficence show up again with this principle; it is not obvious that an individual can be harmed as a donor, assuming a correct declaration of death has been made. Once again, however, it could be argued that transgressing the declared wishes of the decedent would be doing harm.

A more practical application of non-maleficence to presumed consent stems from the importance of a trusting relationship between doctors and patients. Even if the failure of beneficence does not occur as described above, and doctors always do everything they can to save every patient, a presumed consent system could lead patients to think they will be treated as a resource instead of a person in need. Even if no physical harm takes place, the erosion of trust in the patient-medical professional relationship is a real harm. While there is no guarantee this type of suspicion would occur, it is certainly possible and worth consideration. In sum, while non-maleficence cannot be construed to endorse presumed consent, it also cannot be used on its own to condemn it, and we must again defer to another principle.

\section{Justice}

In biomedical ethics, justice mainly applies to the concept of fairness and equal opportunity. Any policy that discriminates against a particular class or group of people would be unjust. One author argues for a presumed consent system on justice grounds by pointing out that any increase in the supply of available organs reduces the need to decide who receives them and who must wait, and thus reduces the potential for wrongful discrimination. This argument, of course, assumes that an opt out policy would increase the organ supply, which we have established is not a given. On the other side of the question, one must consider the possible negative impact of presumed consent on the equal application and administration of healthcare. If the default were to consider everyone a potential donor, one possible outcome could be that doctors with prejudices against certain groups of people might be even more apt to simply view them as a resource to save others. Some evidence already suggests that racial discrimination impacts referral for transplant receipt, as African-Americans are about $23 \%$ less likely than whites to be referred to a transplant center. ${ }^{33}$ Thus, it is not much of a leap in logic to assume discrimination also occurs on the donor end. While there is no direct evidence that presumed consent would exacerbate this type of discrimination, it is a plausible scenario. 
Another possibility is that members of society who choose to opt out of donating could be viewed with contempt. One ethicist bluntly states that if a person has to "take positive action to prevent donation, not donating looks actively mean." ${ }^{34}$ A person who appears miserly or unwilling to help others is prone to mistreatment. Instead of simply looking more favorably upon donors, medical professionals could begin subtle discrimination against the newly created class of explicit non-donors.

Finally, the subversion of justice that would be most likely to occur as a result of opt out policy implementation would be the unequal dissemination of information. Those who are homeless or do not speak one of the major languages might not hear about or properly understand the new system. The failure to opt out could not be taken as tacit consent for people who do not know how the system works, as will be further discussed under autonomy. The possibility that marginalized groups may have their individual rights infringed upon pushes the principle of justice to rule against presumed consent.

\section{Autonomy}

"An autonomous or self-determining person is someone who chooses or devises a plan for her life, rather than having one imposed on her by others or allowing circumstances to dictate one, and proceeds to live in accordance with that plan," explains Robert Young of Latrobe University. ${ }^{35}$ Autonomy is perhaps the most important ethical principle in the discussion of presumed consent, because the most common objection against presumed consent is that it does not give an individual default rights over her body, but instead makes her take an action if she is opposed to donating her organs after death. Assumed in this argument is the idea that every individual has a right to bodily integrity, as propounded by Locke. Locke argues that property, including the body, is the best guarantee of liberty in that it marks a boundary the state cannot cross. ${ }^{36}$ Evidence that this principle continues even after death is found in the traditional sacred nature of burial or cremation and the right of an individual to determine what will be done with his own body postmortem.

Immanuel Kant, the premier proponent of deontological ethics, foundational for principlism, also asserts a relevant ethical claim in his second formulation of the categorical imperative. He asserts that one must "Act so that you treat humanity, whether in your own person or in that of another, always as an end and never as a means only." ${ }^{37}$ The assumption that an individual's organs may be used to save the life of another without explicit consent from the donor is quite clearly an instance of treating the donor as a means. While it is admirable to treat the potential organ recipient as an end and endeavor to give all possible medical aid, the donor candidate must also be treated as an end, which precludes making any unfounded assumptions about what the individual's desires may have been.

From a different perspective, proponents of presumed consent claim that the fact that organ donation approval numbers are so much higher than donation rates shows that many people's wishes are actually not being followed. ${ }^{38}$ Under this logic, the autonomy of a greater number of people would be respected under presumed consent. However, it is not clear that approval of organ donation in general implies a personal desire to donate, and it certainly does not imply informed consent. To perform nearly all non-emergency medical procedures, informed consent is required. As Beauchamp and Childress, the premier proponents of modern principlism, write,

If consent is presumed on the basis of what we know about a particular person's choices or values, it reduces to either implied or express consent. If consent is presumed on the basis of a general theory of human goods or of the rational will, the moral situation is more problematic. Consent should refer to an individual's actual choices, not to presumptions about the choices the individual would or should make. ${ }^{39}$ 
True informed consent assumes the requestor has disclosed relevant information, authorized decision makers have decisional capacity, information is in language they can understand such that they can appreciate the implications of the decision, and the communication takes place under circumstances that allow them to make and communicate a free and voluntary informed choice. ${ }^{40}$ The American Medical Association's policy on presumed consent affirms that "donations under presumed consent would be ethically appropriate only if it could be determined that individuals were aware of the presumption that they were willing to donate organs and if effective and easily accessible mechanisms for documenting and honoring refusals to donate had been established." ${ }^{41}$

Whether these standards are met under presumed consent depends on the exact method in which it is implemented. Presumably, informational pamphlets would be disseminated by mail, but there is no guarantee that the information would be successfully delivered, opened by the recipient, or properly understood. It is also not clear how it could be ensured that all occupants received the proper information. Additionally, there is the problem of the homeless and the undocumented. How would people without an official address get the information? All residents could be required by law to attend informational gatherings or return a signed form that affirms understanding and agreement, but it would be just as easy at that point for a person to give explicit consent. Regardless of the exact mechanism used to disseminate information, it is very difficult to assume that all potential donors who are presumed to have consented to organ removal have actually been properly informed. ${ }^{42}$ Without such consent, Justice Cardozo's words in the Schloendorff v. The Society of New York Hospital opinion apply: "Every human being of adult years and sound mind has a right to determine what shall be done with his own body; and a surgeon who performs an operation without his patient's consent, commits an assault, for which he is liable in damages." ${ }^{43}$ While it could be argued that under the current system informed consent on the part of the donor is not always required, such as in the case where the donor's wishes were not explicit and the family decides to donate, the operative concept is that a family member is in the best position to know the potential donor's intent. In fact, Beauchamp and Childress argue that judgment on behalf of once-competent patients should only be made by a representative if there is reason to think the decision may be made as the patient would have wished. The family members should not be deciding based on their own desires but rather based on what they know of their deceased relative's views and values. ${ }^{44}$ Even if one concludes that the current procedures do not adequately follow informed consent, that is hardly reason to move further away from ensuring proper consent. For individual autonomy to truly be respected, consent for the use of organs must be ensured, and consent must be freely given, not presumed. If even one person's organs are removed without true consent as a result of public policy, that would be an institutionalized moral failure.

\section{Conclusion}

To properly frame the ethical discussion of implementing a presumed consent organ donor system in the United States, we began by examining the nature and magnitude of the organ shortage. We then reviewed current first person authorization organ procurement policy and explored what practical changes presumed consent would have on procedures and protocols. Next, we pragmatically considered what type of impact presumed consent legislation would actually have on the number of available transplants, determining that while presumed consent is more likely than not to improve the number of organ donors, it is far from conclusive. Finally, we discussed how each of the four moral pillars of principlism impact the ethical validity of presumed consent. Beneficence considerations involve both the potential donor, potential recipient, and the possible impact presumed consent could have on how medical professionals view future donors. Ultimately, though beneficence toward the donor candidate pushes against presumed consent, the overall principle is not clear enough on its own to make a definitive judgment either way. Non-maleficence is also somewhat against presumed consent due to the possible erosion of doctor-patient trust, but this argument is not conclusive. Justice quite clearly disfavors an opt out policy because of the increased possibility of discrimination against certain groups a doctor may disfavor, against the new class of explicit 
non-donors, and against the homeless and anyone else unlikely to be properly informed about the new system. Autonomy considerations deal presumed consent a principlist deathblow. Because presumed consent treats donors as a means and not an end only, and because a presumed consent system cannot possibly ensure informed, voluntary consent, it cannot be ethically allowable. Due to the lack of conclusive evidence that presumed consent would even have a significant positive impact on donor rates, and more importantly due to the negative ethical implications for the medical field, one must conclude that an opt out organ donor system would be ill-advised and corrosive to biomedical ethical standards.

1"History." Organ Procurement and Transplantation Network. Accessed March 24, 2017. https://optn.transplant.hrsa.gov/learn/about-transplantation/history/.

${ }^{2}$ Wilkinson, T. Martin. Ethics and the Acquisition of Organs. Oxford University Press, 2011. 1.

3 "Data." Organ Procurement and Transplantation Network. Accessed March 24, 2017. https://optn.transplant.hrsa.gov/data/.

${ }^{4}$ Ibid.

${ }^{5}$ Ibid.

${ }^{6}$ Sheehy, Ellen, Suzanne L. Conrad, Lori E. Brigham, Richard Luskin, Phyllis Weber, Mark Eakin, Lawrence Schkade, and Lawrence Hunsicker. "Estimating the number of potential organ donors in the United States." New England Journal of Medicine 349, no. 7 (2003): 671.

7 "Organ Donation Statistics." Organdonor.gov. 2017. Accessed March 24, 2017. https://www.organdonor.gov/statistics-stories/statistics.html\#registration.

${ }^{8}$ Wilkinson, T. Martin. Ethics and the Acquisition of Organs. Oxford University Press, 2011. 6-7.

${ }^{9}$ Crowe, Sam, PhD, and Eric Cohen, PhD. "PCBE: Organ Donation Policy." PCBE: Organ Donation Policy. 2006. Accessed March 23, 2017. https://bioethicsarchive.georgetown.edu/pcbe/background/crowepaper.html.

${ }^{10}$ Arras, John. "Theory and Bioethics." Stanford Encyclopedia of Philosophy. May 18, 2010. Accessed March 24, 2017. https://plato.stanford.edu/entries/theory-bioethics/.

${ }^{11}$ Ibid

${ }^{12}$ Chon, W. J., M. A. Josephson, E. J. Gordon, Y. T. Becker, P. Witkowski, D. J. Arwindekar, A. Naik, J. R. Thistlethwaite, C. Liao, and L. F. Ross. "When the living and the deceased cannot agree on organ donation: a survey of US organ procurement organizations (OPOs)." American Journal of Transplantation 14, no. 1 (2014): 173.

${ }^{13}$ The National Conference of Commissioners on Uniform State Laws. "Revised Uniform Anatomical Gift Act." In Annual Conference Meeting In Its One-Hundred-and-Fifteenth Year Hilton Head, South Carolina. Proceedings. August 26, 2009. Accessed March 23, 2017. 29.

http://www.uniformlaws.org/shared/docs/anatomical_gift/uaga_final_aug09.pdf.

${ }^{14}$ Ibid.

15 "Anatomical Gift Act (2006)." Uniform Law Commission: The National Conference of Commissioners on Uniform State Laws. Accessed March 23, 2017. http://www.uniformlaws.org/Act.aspx?title=Anatomical Gift Act $\% 282006 \% 29$. 
${ }^{16}$ Chon, W. J., M. A. Josephson, E. J. Gordon, Y. T. Becker, P. Witkowski, D. J. Arwindekar, A. Naik, J. R. Thistlethwaite, C. Liao, and L. F. Ross. "When the living and the deceased cannot agree on organ donation: a survey of US organ procurement organizations (OPOs)." American Journal of Transplantation 14, no. 1 (2014): 172-175.

${ }^{17}$ Ibid., 175

${ }^{18}$ Ibid., 174

${ }^{19}$ Wilkinson, T. Martin. Ethics and the Acquisition of Organs. Oxford University Press, 2011. 92

${ }^{20}$ US Department of Health and Human Services. "Health Resources and Services Administration, Healthcare Systems Bureau, 2012 National Survey of Organ Donation Attitudes and Behaviors." Rockville, Maryland: US Department of Health and Human Services (2013). 48.

${ }^{21}$ Ibid., 48

${ }^{22}$ Abadie, Alberto, and Sebastien Gay. "The impact of presumed consent legislation on cadaveric organ donation: a cross-country study." Journal of health economics 25, no. 4 (2006): 599-620.

${ }^{23}$ Ibid., 610

${ }^{24}$ Rithalia, Amber, Catriona McDaid, Sara Suekarran, Lindsey Myers, and Amanda Sowden. "Impact of presumed consent for organ donation on donation rates: a systematic review." Bmj 338 (2009): a3162. 284-287.

${ }^{25}$ Fabre, John. "Presumed consent for organ donation: a clinically unnecessary and corrupting influence in medicine and politics." Clinical Medicine 14, no. 6 (2014): 567-568.

${ }^{26}$ Miranda, B., M. Fernandez Lucas, C. De Felipe, M. Naya, J. M. Gonzalez-Posada, and R. Matesanz. "Organ donation in Spain." Nephrology Dialysis Transplantation 14, no. 3 (1999): 15-21.

${ }^{27}$ Ibid., 568

${ }^{28}$ Ibid., $567-568$

${ }^{29}$ Cameron, Nigel, M. de S. The New Medicine: Life and Death after Hippocrates. Crossway Books, 1992. 25.

30 "AMA Code of Medical Ethics." American Medical Association. 2016. https://www.ama-assn.org/deliveringcare/ama-code-medical-ethics.

${ }^{31}$ Beauchamp, Tom L., and James F. Childress. Principles of biomedical ethics, 5th ed. NY: Oxford University Press, 2001. 170.

${ }^{32}$ Sullivan, Dennis M. "Brain Death and Organ Donation: New Ethical Controversies." Principles of Bioethics Lecture. Cedarville University, Cedarville, OH. 2016.

${ }^{33}$ Beauchamp, Tom L., and James F. Childress. Principles of biomedical ethics, 5th ed. NY: Oxford University Press, 2001. 238.

${ }^{34}$ Richards, Janet Radcliffe. The ethics of transplants: Why careless thought costs lives. Oxford University Press, 2012. 157.

${ }^{35}$ Young, Robert. "Informed consent and patient autonomy." In A Companion to Bioethics, edited by Helga Kuhse and Peter Singer. Malden, MA: Blackwell Publishing, 2001. 441. 
${ }^{36}$ Rae, Scott B., and Paul M. Cox. Bioethics: A Christian Approach in a Pluralistic Age. William B. Eerdmans Publishing Company. 1999. 201.

${ }^{37}$ Rae, Scott B. Moral choices: An introduction to ethics. Harper Collins, 2009. 79.

${ }^{38}$ Welbourn, Hannah. "A principlist approach to presumed consent for organ donation." Clinical Ethics 9, no. 1 (2014): 12.

${ }^{39}$ Beauchamp, Tom L., and James F. Childress. Principles of biomedical ethics, 5th ed. NY: Oxford University Press, 2001. 66.

${ }^{40}$ Iltis, Ana S. "Organ donation, brain death and the family: Valid informed consent." The Journal of Law, Medicine \& Ethics 43, no. 2 (2015): 371.

41 "AMA Code of Medical Ethics." American Medical Association. 2016. https://www.ama-assn.org/deliveringcare/ama-code-medical-ethics. 6.1.4

${ }^{42}$ Upton, Hugh. "Presumed consent and organ donation." Clinical Ethics 7, no. 3 (2012): 144-145.

${ }^{43}$ Wilkinson, T. Martin. Ethics and the Acquisition of Organs. Oxford University Press, 2011. 16

${ }^{44}$ Beauchamp, Tom L., and James F. Childress. Principles of biomedical ethics, 5th ed. NY: Oxford University Press, 2001. 100. 


\section{Bibliography}

1. Abadie, Alberto, and Sebastien Gay. "The impact of presumed consent legislation on cadaveric organ donation: a cross-country study." Journal of health economics 25, no. 4 (2006): 599-620.

2. "AMA Code of Medical Ethics." American Medical Association. 2016. https://www.amaassn.org/delivering-care/ama-code-medical-ethics.

3. "Anatomical Gift Act (2006)." Uniform Law Commission: The National Conference of Commissioners on Uniform State Laws. Accessed March 23, 2017. http://www.uniformlaws.org/Act.aspx?title=Anatomical Gift Act \%282006\%29.

4. Arras, John. "Theory and Bioethics." Stanford Encyclopedia of Philosophy. May 18, 2010. Accessed March 24, 2017. https://plato.stanford.edu/entries/theory-bioethics/.

5. Beauchamp, Tom L., and James F. Childress. Principles of biomedical ethics, 5th ed. NY: Oxford University Press, 2001.

6. Cameron, Nigel, M. de S. The New Medicine: Life and Death after Hippocrates. Crossway Books, 1992.

7. Chon, W. J., M. A. Josephson, E. J. Gordon, Y. T. Becker, P. Witkowski, D. J. Arwindekar, A. Naik, J. R. Thistlethwaite, C. Liao, and L. F. Ross. "When the living and the deceased cannot agree on organ donation: a survey of US organ procurement organizations (OPOs)." American Journal of Transplantation 14, no. 1 (2014): 172-177.

8. Crowe, Sam, PhD, and Eric Cohen, PhD. "PCBE: Organ Donation Policy." PCBE: Organ Donation Policy. 2006. Accessed March 23, 2017. https://bioethicsarchive.georgetown.edu/pcbe/background/crowepaper.html.

9. "Data." Organ Procurement and Transplantation Network. Accessed March 24, 2017. https://optn.transplant.hrsa.gov/data/.

10. Fabre, John. "Presumed consent for organ donation: a clinically unnecessary and corrupting influence in medicine and politics." Clinical Medicine 14, no. 6 (2014): 567-571.

11. "History." Organ Procurement and Transplantation Network. Accessed March 24, 2017. https://optn.transplant.hrsa.gov/learn/about-transplantation/history/.

12. Iltis, Ana S. "Organ donation, brain death and the family: Valid informed consent." The Journal of Law, Medicine \& Ethics 43, no. 2 (2015): 369-382.

13. The National Conference of Commissioners on Uniform State Laws. "Revised Uniform Anatomical Gift Act." In Annual Conference Meeting In Its One-Hundred-and-Fifteenth Year Hilton Head, South Carolina. Proceedings. August 26, 2009. Accessed March 23, 2017. http://www.uniformlaws.org/shared/docs/anatomical_gift/uaga_final_aug09.pdf.

14. "Organ Donation Statistics." Organdonor.gov. 2017. Accessed March 24, 2017. https://www.organdonor.gov/statistics-stories/statistics.html\#registration. 
15. Rae, Scott B. Moral choices: An introduction to ethics. Harper Collins, 2009.

16. Rae, Scott B., and Paul M. Cox. Bioethics: A Christian Approach in a Pluralistic Age. William B. Eerdmans Publishing Company. 1999.

17. Richards, Janet Radcliffe. The ethics of transplants: Why careless thought costs lives. Oxford University Press, 2012.

18. Rithalia, Amber, Catriona McDaid, Sara Suekarran, Lindsey Myers, and Amanda Sowden. "Impact of presumed consent for organ donation on donation rates: a systematic review." Bmj 338 (2009): a3162.

19. Sheehy, Ellen, Suzanne L. Conrad, Lori E. Brigham, Richard Luskin, Phyllis Weber, Mark Eakin, Lawrence Schkade, and Lawrence Hunsicker. "Estimating the number of potential organ donors in the United States." New England Journal of Medicine 349, no. 7 (2003): 667-674.

20. Sullivan, Dennis M. "Brain Death and Organ Donation: New Ethical Controversies." Principles of Bioethics Lecture. Cedarville University, Cedarville, OH. 2016.

21. Upton, Hugh. "Presumed consent and organ donation." Clinical Ethics 7, no. 3 (2012): 142-146.

22. US Department of Health and Human Services. "Health Resources and Services Administration, Healthcare Systems Bureau, 2012 National Survey of Organ Donation Attitudes and Behaviors." Rockville, Maryland: US Department of Health and Human Services (2013).

23. Welbourn, Hannah. "A principlist approach to presumed consent for organ donation." Clinical Ethics 9, no. 1 (2014): 10-16.

24. Wilkinson, T. Martin. Ethics and the Acquisition of Organs. Oxford University Press, 2011.

25. Young, Robert. "Informed consent and patient autonomy." In A Companion to Bioethics, edited by Helga Kuhse and Peter Singer. Malden, MA: Blackwell Publishing, 2001. 